\title{
Selective extraction of phospholipids from whey protein phospholipid concentrate using supercritical carbon dioxide and ethanol as a co-solvent
}

\author{
B. Sprick, ${ }^{1}$ Z. Linghu, ${ }^{1}$ J. K. Amamcharla, ${ }^{1,2 *}$ L. E. Metzger, ${ }^{3}$ and J. S. Smith ${ }^{1,2}$ \\ ${ }^{1}$ Food Science Institute, Kansas State University, Manhattan 66506 \\ ${ }^{2}$ Department of Animal Sciences and Industry, Kansas State University, Manhattan 66506 \\ ${ }^{3}$ Department of Dairy and Food Science, Midwest Dairy Foods Research Center, South Dakota State University, Brookings 57007
}

\section{ABSTRACT}

In recent years, using dairy phospholipids (PL) as functional ingredients has increased because PL have nutritional benefits and functional properties. In this study, a novel 2-step supercritical fluid extraction (SFE) process was used to extract whey protein phospholipid concentrate (WPPC), a dairy co-product obtained during the manufacture of whey protein isolate, for PL enrichment. In the first step, nonpolar lipids in WPPC were removed using neat supercritical carbon dioxide $\left(\mathrm{S}-\mathrm{CO}_{2}\right)$ at $41.4 \mathrm{MPa}$ and $60^{\circ} \mathrm{C}$. In the second stage, the feasibility of using the polar solvent ethanol as a co-solvent to increase the solubility of $\mathrm{S}^{-\mathrm{CO}_{2}}$ extraction solvent was explored. A $3 \times 3 \times 2$ factorial design with extraction pressure $(35.0,41.4$, and $55.0 \mathrm{MPa})$, temperature $\left(40\right.$ and $60^{\circ} \mathrm{C}$ ), and concentration of ethanol $(10,15$, and $20 \%)$ as independent factors was used to evaluate the extraction efficiency providing the most total PL, and the best proportion of each individual PL from the spent solids collected during $\mathrm{S}_{-} \mathrm{CO}_{2} \mathrm{SFE}$. All lipid fractions were analyzed using thin-layer chromatography and high-performance lipid chromatography. The total amount of PL extracted from WPPC was significantly affected by ethanol concentration; the extraction pressure and temperature were nonsignificant. The optimal SFE condition for generating a concentrated PL lipid fraction was $35.0 \mathrm{MPa}, 40^{\circ} \mathrm{C}$, and $15 \%$ ethanol concentration; the highest amount of extracted PL averaged $26.26 \mathrm{~g} / 100 \mathrm{~g}$ of fat. Moreover, adjusting SFE condition allowed successful recovery of a high concentration of sphingomyelin, phosphatidylcholine, and phosphatidylethanolamine, giving averages of $11.07,10.07$, and $7.2 \mathrm{~g} / 100 \mathrm{~g}$ of fat, respectively, 2 to 3 times more than conventional solvent extraction. In addition, exhausted solids obtained after the SFE process

Received February 2, 2019.

Accepted August 7, 2019.

*Corresponding author: Jayendra@ksu.edu were enriched with denatured proteins $(72 \%$ on dry basis) with significantly more water-holding capacity and emulsifying capacity than untreated WPPC. Overall, this 2-stage SFE process using neat $\mathrm{S}_{-} \mathrm{CO}_{2}$ and ethanol has the greatest potential to produce a PL-rich lipid fraction from WPPC.

Key words: supercritical fluid extraction, whey protein phospholipid concentrate

\section{INTRODUCTION}

Phospholipids (PL) are a complex class of amphiphilic lipids that contain both polar (phosphate group) and nonpolar (fatty acid chain) properties (Ishihara et al., 1992). As an important constituent of cell membranes, the major PL fractions are sphingomyelin (SM), phosphatidylcholine (PC), phosphatidylethanolamine (PE), phosphatidylinositol (PI), and phosphatidylserine (PS; Contarini and Povolo, 2013). In milk fat, PL associated with milk proteins and other nonpolar lipids (e.g., cholesterol and triglycerides) are largely found in the milk fat globule membrane (MFGM) and maintain the integrity of cell membrane structure (Singh, 2006). In recent years, interest in PL from dairy products has increased because of the growing awareness of their nutritional value. In many epidemiological and in vitro studies, dairy PL with SM and PS in particular are associated with many health benefits such as regulating gastrointestinal infections (Veereman-Wauters et al., 2012), attenuating stress-induced memory impairment (Schubert et al., 2011), reducing cardiovascular risk factors (Hartmann et al., 2009), and inhibiting cholesterol absorption (Kamili et al., 2010). Moreover, PL actively suppress colorectal cancer (Kuchta et al., 2012) and help improve cognitive performance of those suffering from Alzheimer's disease (Rombaut et al., 2007). Likewise, digestion products of PL, including ceramides and sphingosine, are essential to cell regulation; they modulate cell growth, differentiation, proliferation, and transmembrane signaling (Astaire et al., 2003; Contarini and Povolo, 2013). Dairy PL are excellent emulsi- 
fiers because of their distinctive amphiphilic properties and can be used as an alternative to industrial lecithin to stabilize emulsion systems in foods (Gülseren et al., 2012).

Milk and other dairy products, particularly butter serum and buttermilk, are natural sources of PL (Morin et al., 2004; Costa et al., 2010). Whey protein phospholipid concentrate (WPPC), also called procream, is a co-product generated during microfiltration of whey protein isolate (WPI; Levin et al., 2016). The chemical composition of WPPC is similar to buttermilk powder and contains comparatively high amounts of proteins (50-69\%), lipids (11-38\%) from MFGM, and water, lactose, and minerals (7-20\%; Levin et al., 2016). The PL content of WPPC was estimated at 10 to $45.8 \%$ of total fat content, compared with $12.4 \%$ for buttermilk, $5.65 \%$ for butter, and $5.65 \%$ for whey cream (Costa et al., 2010; Levin et al., 2016). Bund and Hartel (2013) replaced nonfat dry milk with a mixture of WPPC and delactosed whey permeate in ice cream and found no significant difference in off-flavor and flavor acceptability. Levin et al. (2016) suggested WPPC as a potentially novel ingredient that had good emulsifying properties that could be used as natural emulsifier to replace synthetics in ice cream. In the dairy industry WPPC is produced in large quantities during manufacture as a co-product but is underused as mostly in animal feed or spread on fields. Whey protein phospholipid concentrate, however, may serve as a lowcost, concentrated source of bioactive PL, a practical and economical alternative emulsifier.

Current technologies for extracting diary PL have used enzymatic hydrolysis (Barry et al., 2017), filtration (e.g., microfiltration and UF; Astaire et al., 2003; Costa et al., 2010), and tandem solvent extraction (e.g., hexane or ethanol; Contarini and Povolo, 2013). The microfiltration process has been the preferred method for PL extraction because of its high extraction efficiency and low consumption of organic solvents (Corredig et al., 2003; Hauff and Vetter, 2009). However, high retention of co-extracted proteins and nonpolar lipids occurred during filtration, limiting the feasibility of microfiltration for producing purified PL fractions (Morin et al., 2004). Recently, the supercritical fluid extraction (SFE) technique has been widely studied in the food industry (Nisha et al., 2012). By taking advantage of supercritical solvents, SFE provides high selectivity for extracting natural components from complex matrices (Nisha et al., 2012). In many applications of $\mathrm{SFE}$, supercritical carbon dioxide $\left(\mathbf{S}-\mathbf{C O}_{2}\right)$ is the most commonly used solvent because it is chemically inert, nontoxic, and nonflammable as well as commercially available (Zhong and Jin, 2008). Thus, SFE may be a promising and clean food processing technique that can successfully extract nonpolar lipid compounds such as vitamins (A, D, E, and $\mathrm{K}$ ), essential oils, total meat fats, and cholesterol (Astaire et al., 2003; Herrero et al., 2006; Khaw et al., 2017). Astaire et al. (2003) showed that by combining microfiltration and the SFE-S- $\mathrm{CO}_{2}$ process $\left(37.5 \mathrm{mPa}\right.$ and $\left.77^{\circ} \mathrm{C}\right)$ the most nonpolar lipids from buttermilk powders could be effectively removed, resulting in increased PL content of MFGM from 31.02 to $83.15 \mathrm{~g} / 100 \mathrm{~g}$ of dry powder. Spence et al. $(2009 \mathrm{a}, \mathrm{b})$ and Costa et al. (2010) carried out similar studies where the SFE-S- $\mathrm{CO}_{2}$ process was used to remove nonpolar lipids while concentrating PL mixtures from whey buttermilk, whey cream, and whey butter. However, these studies using the SFE-S-CO $\mathrm{CO}_{2}$ process could not extract a high-purity PL fraction. The neat $\mathrm{S}_{-} \mathrm{CO}_{2}$ cannot efficiently solubilize PL moieties (Montanari et al., 1996), leaving a high amount of valuable PL in the residual extracts mixed with milk proteins and nonpolar lipids. Generating a purified PL fraction requires postextraction steps.

Montanari et al. (1999) used the polar solvent ethanol as a co-solvent to improve solubility of PL in neat $\mathrm{S}-\mathrm{CO}_{2}$ extraction, and demonstrated that PL were selectively extracted from soybean flakes during the SFE process. Elst et al. (2003) confirmed that ethanol could enhance $\mathrm{S}-\mathrm{CO}_{2}$ polarity, and with an increase in ethanol concentration $(\geq 5 \mathrm{~mol})$, PL recovery from egg yolk powder was significantly improved. However, only a few studies have used the SFE-S-CO $\mathrm{CO}_{2}$ process with ethanol to extract PL from dairy products. A recent study (Barry et al., 2017) applied the SFE-S- $\mathrm{CO}_{2}$ process with $20 \%$ ethanol to buttermilk powders to concentrate PL, achieving up to $56.24 \%$ extraction of PL in dry mass. However, in these studies, pre-extraction processes of enzymatic hydrolysis and UF were needed to facilitate PL enrichment before SFE extraction. Thus, our objective in this study was to develop and evaluate a novel 2-step SFE process to remove nonpolar lipids and recover PL fractions simultaneously from WPPC. To achieve this objective, neat $\mathrm{S}-\mathrm{CO}_{2}$ was first applied to remove nonpolar lipids from WPPC and ethanol was used as co-solvent in the SFE-S- $\mathrm{CO}_{2}$ process during the second stage of extraction. To determine the optimal SFE extraction setting, we varied extraction temperature, extraction pressure, and concentration of ethanol. Total PL content as well as the proportion of each individual PL recovered from WPPC samples were quantified. We also investigated functional properties of residual WPPC extracts after the SFE process was completed. 


\section{MATERIALS AND METHODS}

\section{Materials}

Three lots of WPPC powders were obtained from a commercial manufacturer in the United States. All chemical solvents were HPLC grade and obtained from Fisher Scientific (Atlanta, GA). The reference standards of PL including PC (from egg yolk, $\geq 99 \%$ ), PE (from egg yolk, $\geq 99 \%$ ), and SM (from egg yolk, $\geq 99 \%$ ) were purchased from Sigma-Aldrich (St. Louis, MO). Silica gel thin layer chromatography (TLC) plates were purchased from EMD Chemicals (Darmstadt, Germany), and the developing tank was from Kontes Glass Company (Vineland, NJ).

\section{Compositional Analysis}

The CP measurement of WPPC control samples was carried out with a Leco protein analyzer (Leco Corp., St. Joseph, MI) according to AOAC method 945.46 (AOAC International, 2016). The percent protein content was calculated using the milk protein conversion factor of 6.38. Total solids were determined using the forced air method (method 990.20; AOAC International, 2016). Ash content was measured using the incineration method (method 954.46; AOAC International, 2016). Fat content was determined with a CEM Smart Trac system (CEM Corp., Matthews, NC) using AOAC method 989.05 (AOAC International, 2016). Fat results were reported by CEM system as a percentage by weight. The compositional analysis was performed in duplicate.

\section{Conventional Solvent Extraction of Polar Lipids}

Polar lipids extraction from WPPC samples was carried out using the liquid-liquid extraction (LLE) method as described by Rombaut et al. (2007), with minor modifications. Briefly, $5 \mathrm{~g}$ of WPPC powder was dissolved in deionized water to make $20 \mathrm{~mL}$ of slurry. The slurry was then mixed with $80 \mathrm{~mL}$ of chloroform: methanol 2:1 (vol:vol) and transferred into a separatory funnel. After shaking for $2 \mathrm{~min}$, the mixture was allowed to stand and separate. The lower chloroform phase was collected from the mixture. The upper aqueous phase was washed with $40 \mathrm{~mL}$ of chloroform: methanol 20:1 (vol:vol) and the lower chloroform phase was collected again. This step was repeated twice. The remaining aqueous phase was collected and mixed with $40 \mathrm{~mL}$ of chloroform:methanol:water 85:14:1 (vol:vol: vol) with $1 \mathrm{~N} \mathrm{HCl}$. Following this, the chloroform phase was washed with a $0.9 \%$ (wt/wt) of $\mathrm{NaCl}$ solution un- til neutral pH was reached. Finally, all 4 chloroform phases were combined and evaporated in a water bath at 37 to $39^{\circ} \mathrm{C}$ using a rotary vacuum evaporator (Buchi, Flawil, Switzerland) to remove solvent. The crude polar lipids extract $(1 \mathrm{mg})$ was re-concentrated with $1 \mathrm{~mL}$ of methanol, filtered, and transferred into capped sample vial for PL composition analysis. The LLE process was carried out in duplicate.

\section{Supercritical Fluid Extraction (SFE)}

In this study, a unique 2-step SFE process was developed for PL extraction from WPPC samples. The process flow diagram for PL extraction is shown in Figure 1. A laboratory-scale SFE system (Applied Separations, Allentown, PA) fitted with a 32-mL stainless steel extraction vessel was used (Figure 2). Before extraction, approximately $20 \mathrm{~g}$ of each WPPC powder was mixed with glass beads (Fisher Scientific, Atlanta, GA) in a ratio of 2:1 and packed in an extraction vessel as suggested by the manufacturer. Dispersing filler was then added to the remaining empty space in the vessel and sealed as per the instructions provided by the manufacturer.

Step 1: Nonpolar Lipids Removal. In the initial SFE stage, WPPC samples were subjected to $\mathrm{S}_{-} \mathrm{CO}_{2}$ only to remove most of nonpolar lipids. The extraction conditions were as follows: extraction pressure, 41.4 $\mathrm{MPa}$; temperature, $60^{\circ} \mathrm{C}$; flow rate, $5 \mathrm{~L} / \mathrm{min}$; soaking time, $30 \mathrm{~min}$; and total running time, $90 \mathrm{~min}$. Following the treatment, lipid extract was collected into a $30-\mathrm{mL}$ collection vial, whereas $\mathrm{CO}_{2}$ was released into the environment. This process was repeated several times until approximately $180 \mathrm{~g}$ of spent solids (WPPC residue enriched in polar lipids) was collected for further analysis. The extracted fractions containing nonpolar lipids from SFE were analyzed for lipids profile by TLC.

Step 2: PL Extraction. In the subsequent stage, ethanol as a co-solvent was used with $\mathrm{S}_{-} \mathrm{CO}_{2}$ to facilitate polar lipid extraction from spent solids, which were produced after neat $\mathrm{S}-\mathrm{CO}_{2}$ extraction. To maximize the extraction efficiency, the operating conditions of SFE were optimized by employing a $3 \times 3 \times 2$ factorial design, in which extraction pressure, temperature, and ethanol concentration were studied as independent variables. Three levels of pressure were chosen at 35.0, 41.4 , and $55.0 \mathrm{MPa}, 2$ levels of temperature were set up at 40 and $60^{\circ} \mathrm{C}$, and 3 levels of ethanol concentration were at 10,15 , and $20 \%$ (mole fraction of $\mathrm{CO}_{2}$ ). Following the treatment, ethanol from the extracted fraction was removed under a gentle stream of air in a hood. The residual polar lipids were weighted and subjected to lipid profile analysis by TLC and PL composition 


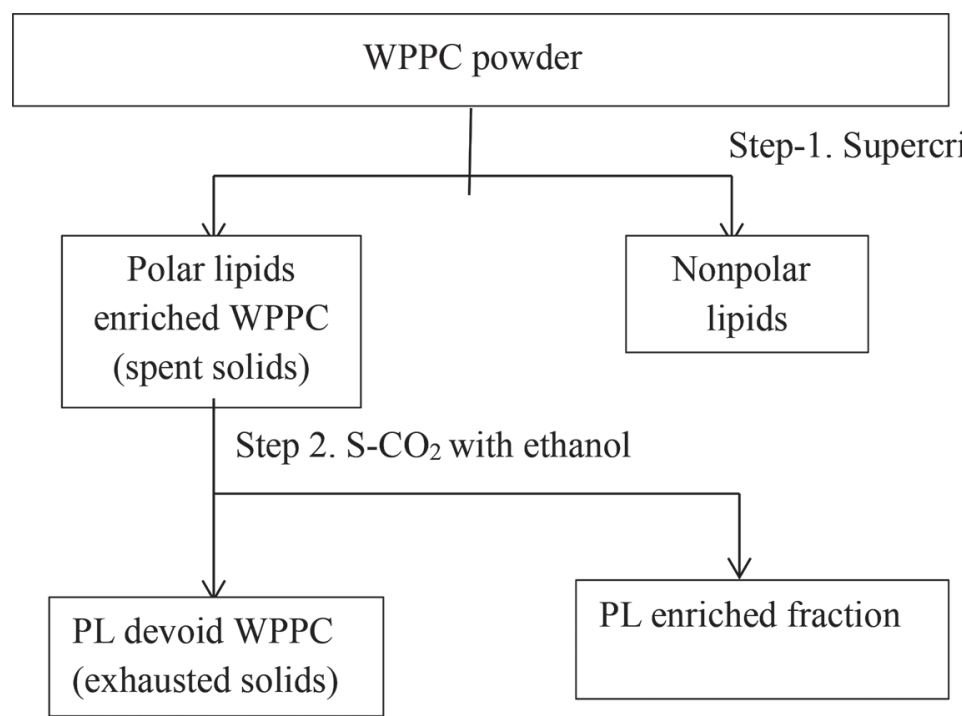

Figure 1. Flow diagram for supercritical fluid extraction process for phospholipid (PL) extraction from whey protein phospholipid concentrate (WPPC) powder.

analysis by HPLC with no further treatment. The lipids remaining in sample was collected and prefixed as "exhausted solids." The SFE extraction processes were carried out in triplicate.

\section{Analytical Methods for PL}

Lipid Profile Analysis. The lipid profile was analyzed by TLC according to the procedure described by Spence et al. (2009a). The polar lipids were separated using a solvent consisting of chloroform:methanol: deionized water $(65: 25: 4$, vol:vol:vol). Extracted lip- ids sample and pure PL standards were prepared in chloroform:methanol (1:2, vol:vol) at 10 and $1 \mathrm{mg} /$ $\mathrm{mL}$, respectively. Silica gel plates were loaded into a developing tank and applied with $10 \mu \mathrm{g}$ of sample and $5 \mu \mathrm{g}$ of standard using glass capillaries. Lipid spots on TLC plates were visualized by exposure to iodine vapor overnight and identified by comparison with PL standards (Astaire et al., 2003).

HPLC Analysis of PL Composition. The polar lipid extract $(10 \mathrm{mg})$ from the LLE- and SFE-treated WPPC sample was dissolved in $1 \mathrm{~mL}$ of methanol, syringe filtered $(0.2 \mu \mathrm{m}$ filter $)$, and subjected to HPLC

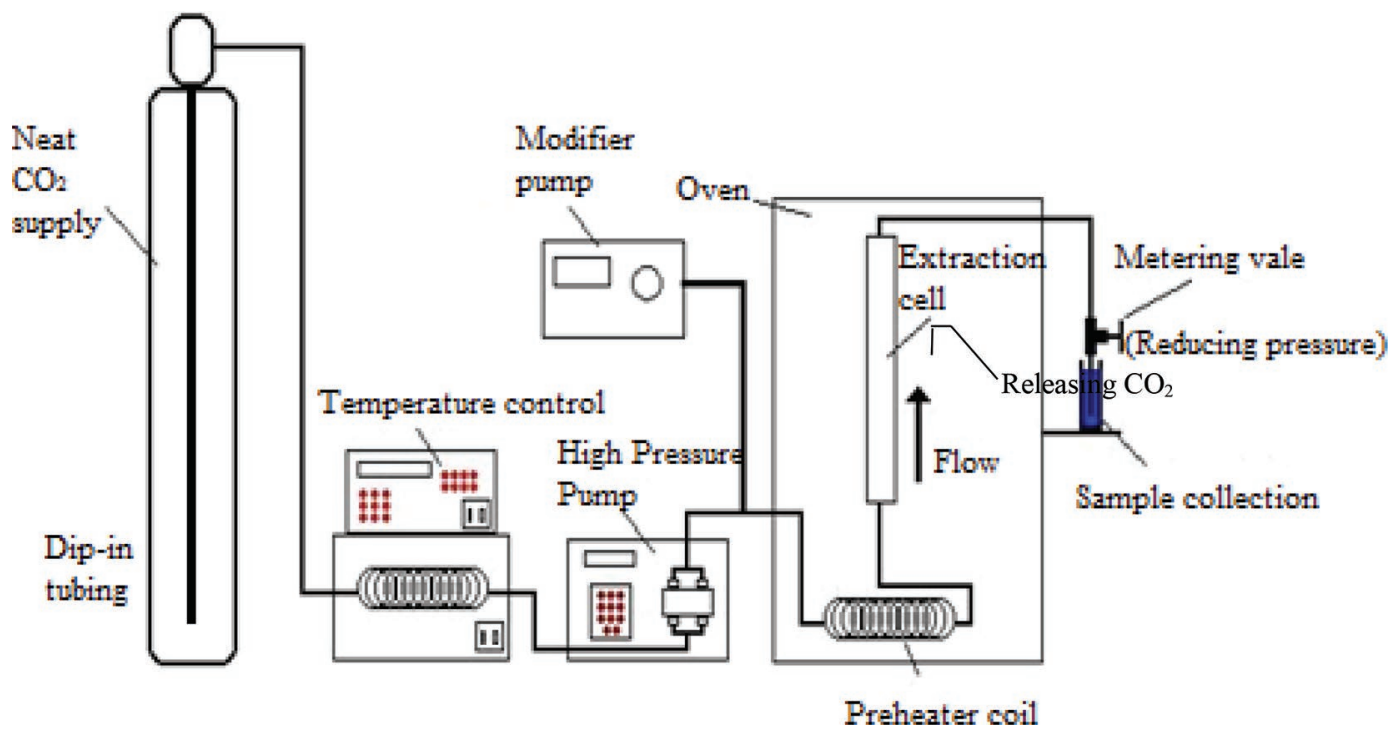

Figure 2. Supercritical fluid extraction apparatus. 
analysis. The PL composition was carried out on an HP 1050 Series HPLC (Agilent Technologies, Santa Clara, CA) equipped with an HP 1050 Series diode array UVvisible detector. The chromatographic separation of PL was achieved on a Luna HILIC column $(150 \mathrm{~mm} \times 4.6$ $\mathrm{mm}$ i.d., $5 \mu \mathrm{m}$ ) from Phenomenex Inc. (Le Pecq Cedex, France) and a linear binary gradient using mobile phase $\mathrm{A}$ as water and mobile phase $\mathrm{B}$ as acetonitrile at a flow rate of $1 \mathrm{~mL} / \mathrm{min}$. The column temperature was set at $35^{\circ} \mathrm{C}$. The initial mobile phase percentage started with $10 \%$ mobile B for 3 min and then linearly increased to $50 \%$ over a course of $22 \mathrm{~min}$. The UV detection wavelength for PC, PE, and SM was at $203 \mathrm{~nm}$ as determined by Wang et al. (2003). Data were recorded and analyzed by ChemStation Software Rev A.10.02 (Agilent Technologies). The identification of SM, PC, and $\mathrm{PE}$ was achieved by comparing retention times to external standards and their content was quantified using a calibration curve $\left(\mathrm{R}^{2}>0.99\right)$. The quantitative and qualitative assessment of individual PL in WPPC were carried out using PL (SM, PC, and PE) extracted from egg yolk as standards. Previous studies have reported that the fatty acid compositions and ratios of saturated to unsaturated fatty acids of PC and PE isolated from egg yolk are comparable to that of derived from bovine milk, with palmitic acid (C16:0), stearic acid (C18:0), oleic acid (C18:1), and linoleic acid (18:2) as the major fatty acids (Hawke, 1959; Chojnacka et al., 2009; Sánchez-Juanesa et al., 2009). In addition, both egg and milk SM contained a high amount $(>95 \%)$ of SFA (Noh and Koo, 2004). For the quantitative analysis of PL, the calibration curves for SM (0.01-1.0 mg), PC (0.01-1.0 mg), and PE (0.01-1.0 mg) were calculated by plotting the concentration against its peak area values. The linear regression analysis showed that all PL had the high coefficient of determination $\left(R^{2}>0.99\right)$, demonstrating that the UV response throughout the concentration range was linear.

\section{Functional Analysis}

Water-holding capacity and emulsifying capacity of exhausted solids obtained after step 2 SFE treatment with $55 \mathrm{MPa}, 40^{\circ} \mathrm{C}$, and $15 \%$ ethanol were examined and compared with WPPC control samples (no treatment with LLE and SFE).

Water-Holding Capacity. The water-holding capacity (WHC) was determined according to the method described by Veith and Reynolds (2004) with some modifications. Briefly, $15 \%$ (wt/vol) sample solution was prepared at room temperature and $\mathrm{pH}$ was adjusted to neutral ( $\mathrm{pH} 7.0$ ) with $1 \mathrm{~N} \mathrm{NaOH}$ or $\mathrm{HCl}$. The solution was stirred for $10 \mathrm{~min}$, transferred into a 30-mL capped plastic tube, and then heated in a water bath at $70^{\circ} \mathrm{C}$ for $70 \mathrm{~min}$. Gels were cooled at $20^{\circ} \mathrm{C}$, then cut into $10-\mathrm{mm}$-length slices right before testing. These gel slices were weighed and placed between a folded tissue paper with a cheese screen inside. A plastic plate was put on top of the tissue and slices were compressed with $1 \mathrm{~kg}$ of weight for $10 \mathrm{~min}$. The WHC was determined as the percentage of the initial water remaining in the gel after compression.

Emulsifying Capacity. Protein solution at 5\% (wt/vol) was prepared by dispersing WPPC powders or exhausted solids into deionized water at $40^{\circ} \mathrm{C}$, and agitating at a rate of $800 \mathrm{rpm}$ for $5 \mathrm{~min}$ followed by $500 \mathrm{rpm}$ for $25 \mathrm{~min}$ using an overhead stirrer (Caframo, Ontario, Canada). Protein dispersions were later stored at $4^{\circ} \mathrm{C}$ overnight to allow protein hydrations. After hydration, a $25 \mathrm{~mL}$ of protein dispersion was equilibrated at $25^{\circ} \mathrm{C}$ in a water bath before mixing. Canola oil was slowly added into dispersion at rate of $1 \mathrm{~mL} / \mathrm{s}$ and continuously blended using a homogenizer (PolyScience, Niles, IL). The emulsion formation and inversion were monitored by a portable waterproof conductivity meter. The end point of adding oil was determined when the conductivity was 0 , where the inversion point of the sample was reached. The amount of oil used was recorded and emulsifying capacity was expressed as the percentage of canola oil retained in $5 \%$ protein dispersions until phase inversion.

\section{Statistical Analysis}

Effects of extraction temperature, pressure, and ethanol concentration on the extraction of PL from WPPC were analyzed using the PROC GLIMMIX procedure of SAS (version 9.4, SAS Institute Inc., Cary, NC). The mean value comparisons were performed by Tukey's test and the $P$-value was set at 0.05 .

\section{RESULTS AND DISCUSSION}

\section{Composition Analysis}

The chemical composition of WPPC was analyzed before LLE and SFE treatments. As shown in Table 1, moisture, fat, protein, and ash were significantly different among 3 lots of WPPC. The total protein and fat content showed the most difference, with protein content ranging from 56.64 to $64.99 \%$ and fat content from 18.46 to $24.23 \%$, whereas ash content showed differences ranging from 2.27 to $2.57 \%(P<0.05)$. To be specific, WPPC\#1 had more significant amounts of total fat and ash content although protein and moisture contents were much lower than WPPC\#2 and WPPC\#3 $(P<0.05)$. These differences could be attributable to commercial origin and lots. Because 
Table 1. Proximate composition of 3 lots of whey protein phospholipid concentrate (WPPC) from each manufacturer $^{1}$

\begin{tabular}{lcccc}
\hline $\begin{array}{l}\text { WPPC } \\
\text { lot }\end{array}$ & $\begin{array}{c}\text { Moisture } \\
(\%)\end{array}$ & $\begin{array}{c}\text { Fat } \\
(\%)\end{array}$ & $\begin{array}{c}\text { Protein } \\
(\%)\end{array}$ & $\begin{array}{c}\text { Ash } \\
(\%)\end{array}$ \\
\hline 1 & $2.99 \pm 0.05^{\mathrm{a}}$ & $24.23 \pm 0.01^{\mathrm{a}}$ & $56.64 \pm 0.03^{\mathrm{a}}$ & $2.57 \pm 0.02^{\mathrm{a}}$ \\
2 & $3.61 \pm 0.02^{\mathrm{b}}$ & $18.71 \pm 0.06^{\mathrm{b}}$ & $64.82 \pm 0.08^{\mathrm{b}}$ & $2.31 \pm 0.00^{\mathrm{b}}$ \\
3 & $4.03 \pm 0.03^{\mathrm{c}}$ & $18.46 \pm 0.01^{\mathrm{b}}$ & $64.99 \pm 0.04^{\mathrm{b}}$ & $2.27 \pm 0.02^{\mathrm{b}}$ \\
\hline
\end{tabular}

${ }^{\mathrm{a}-\mathrm{c}}$ Means within a column with different superscripts differ $(P<0.05)$.

${ }^{1} \mathrm{n}=2 ;$ mean \pm relative deviations from the mean.

WPPC is a co-product produced during microfiltration of whey protein concentrate, variations in the chemical properties of whey protein concentrate as feed material as well as microfiltration processing might significantly affect the initial composition of WPPC (Levin et al., 2016). Levin et al. (2016) found that the chemical composition of WPPC could be highly variable among suppliers. The American Dairy Products Institute (2016) provides minimum standards for WPPC for protein (50\%), fat (12\%), ash (8\%), and moisture content (6\%), so the WPPC samples we used in this study, with an average $62.15 \%$ protein and $20.46 \%$ fat, fell well within the standard, although moisture and ash were slightly below the limit, with $2.39 \%$ ash and $3.54 \%$ moisture.

\section{PL Composition of LLE-Treated WPPC}

Table 2 shows total PL extracted from WPPC samples using LLE as well as each individual PL extracted. This analysis was done using tandem-solvent extraction and quantified with HPLC. The total PL content among 3 lots of WPPC varied from 10.42 to 13.24 $\mathrm{g} / 100 \mathrm{~g}$ of fat, corresponding to 1.78 to $2.20 \mathrm{~g} / 100 \mathrm{~g}$ of WPPC on a dry basis. The observed variability in total $\mathrm{PL}$ is probably due to the initial variability in total lipids of WPPC. The total PL content of the WPPC was lower than what companies advertise (up to 20 $\mathrm{g} / 100 \mathrm{~g}$ of WPPC), but Levin et al. (2016) reported similar results with an average 62 to $74 \mathrm{~g}$ of PL/100 $\mathrm{g}$ of fat extracted from WPPC using the AOAC fat removal method and measured with GC. Extraction efficiency for PL changes by fat extraction method, so the differences are probably because the majority of PL were chemically bound to whey protein aggregates via a noncovalent bond in the MFGM, which limits quantification of PL unless the bond is broken (Levin et al., 2016). In addition, the major PL extracted from WPPC were SM (24.56 to $30.49 \%$ of the total PL), PC (22.28 to $28.67 \%$ of the total PL), and PE (46.77 to $47.23 \%$ of total PL; Table 2).

\section{Evaluating 2-Stage SFE Process on Total PL Recovery from WPPC}

Step 1: Nonpolar Lipids Removal. In the first step of SFE extraction, neat $\mathrm{S}-\mathrm{CO}_{2}$ was used as the extraction solvent to remove nonpolar lipids from 3 lots of WPPC, leaving high-purity polar lipids in the spent solids. Analysis of lipid profiles was done with TLC. Figure 3 shows a picture of a TLC plate obtained for untreated WPPC (as control), spent solids, and extracted fraction taken from the spent solids after the first SFE extraction at $41.4 \mathrm{MPa}$ and $60^{\circ} \mathrm{C}$. Residual lipids in the spent solids (Figure 3, lane 2) contained most of the polar lipids with PE, PC, and SM clearly separated on TLC. Compared with the control (Figure 3 , lane 1 ), the relatively higher intensity of PL bands for the spent solids indicated a high proportion of $\mathrm{PL}$ was enriched in the spent solids after neat $\mathrm{S}-\mathrm{CO}_{2} \mathrm{SFE}$. Moreover, Figure 3 (lane 3) shows that the extracted

Table 2. The total phospholipids (PL; dry basis and fat basis), sphingomyelin (SM), phosphatidylcholine (PC), and phosphatidylethanolamine (PE) content (fat basis) of liquid-liquid extracted-whey protein phospholipid concentrate (WPPC) from $3 \operatorname{lots}^{1}$

\begin{tabular}{|c|c|c|c|c|c|c|c|c|}
\hline \multirow{2}{*}{$\begin{array}{l}\text { WPPC } \\
\text { lot }\end{array}$} & \multicolumn{6}{|c|}{ PL species } & \multicolumn{2}{|c|}{ Total PL } \\
\hline & \multicolumn{2}{|c|}{ SM } & \multicolumn{2}{|c|}{$\mathrm{PC}$} & \multicolumn{2}{|c|}{$\mathrm{PE}$} & $\begin{array}{l}\text { Dry basis } \\
(\mathrm{g} / 100 \mathrm{~g})\end{array}$ & $\begin{array}{l}\text { Fat basis } \\
(\mathrm{g} / 100 \mathrm{~g})\end{array}$ \\
\hline 1 & $2.56 \pm 0.00^{\mathrm{a}}$ & 24.56 & $2.99 \pm 0.17^{\mathrm{a}}$ & 28.67 & $4.87 \pm 0.02^{\mathrm{a}}$ & 46.77 & $1.78^{\mathrm{a}}$ & $10.42^{\mathrm{a}}$ \\
\hline 2 & $4.09 \pm 0.02^{\mathrm{b}}$ & 30.49 & $2.99 \pm 0.01^{\mathrm{a}}$ & 22.28 & $6.34 \pm 0.04^{\mathrm{b}}$ & 47.23 & $2.20^{\mathrm{b}}$ & $13.42^{\mathrm{b}}$ \\
\hline
\end{tabular}

${ }^{\mathrm{a}-\mathrm{c}}$ Means within a column with different superscripts differ $(P<0.05)$.

${ }^{1} \mathrm{n}=2$; mean \pm relative deviations from the mean. 
fraction was composed of exclusively nonpolar lipids, confirming that a large amount of unwanted nonpolar lipids was efficiently removed from WPPC using SFE-S-CO $\mathrm{CO}_{2}$ process $\left(41.4 \mathrm{MPa}\right.$ and $60^{\circ} \mathrm{C}$ ) and no residual polar lipids were removed. Astaire et al. (2003) reported similar results using $\mathrm{SFE}$ with neat $\mathrm{S}-\mathrm{CO}_{2}$ at $37.5 \mathrm{MPa}$ and $77^{\circ} \mathrm{C}$ treatment, which reduced lipid content (mostly nonpolar lipids) from 5 to $1.5 \%$ from micro-filtered buttermilk powders. Costa et al. (2010) also reported removing $\sim 72 \%$ nonpolar lipids from buttermilk powder using SFE-S-CO $\mathrm{CO}_{2}$ at $35.0 \mathrm{MPa}$ and $50^{\circ} \mathrm{C}$. However, very little of the nonpolar lipids remained in the spent solids (Figure 3, lane 2), and they were carried over to step 2 of the extraction. Astaire et al. (2003) and Costa et al. (2010) reported that cholesterol and nonpolar lipids particularly triacylglycerides with short- and medium-chain fatty acids $(\leq \mathrm{C} 18: 1)$ from buttermilk powder were separated from buttermilk powder after SFE-S-CO ${ }_{2}$, whereas free fatty acids, mono-, di-, and triacylglycerides containing long-chain fatty acids (C18:2 to C24) were preferentially retained in the spent solids after step 1 extraction.

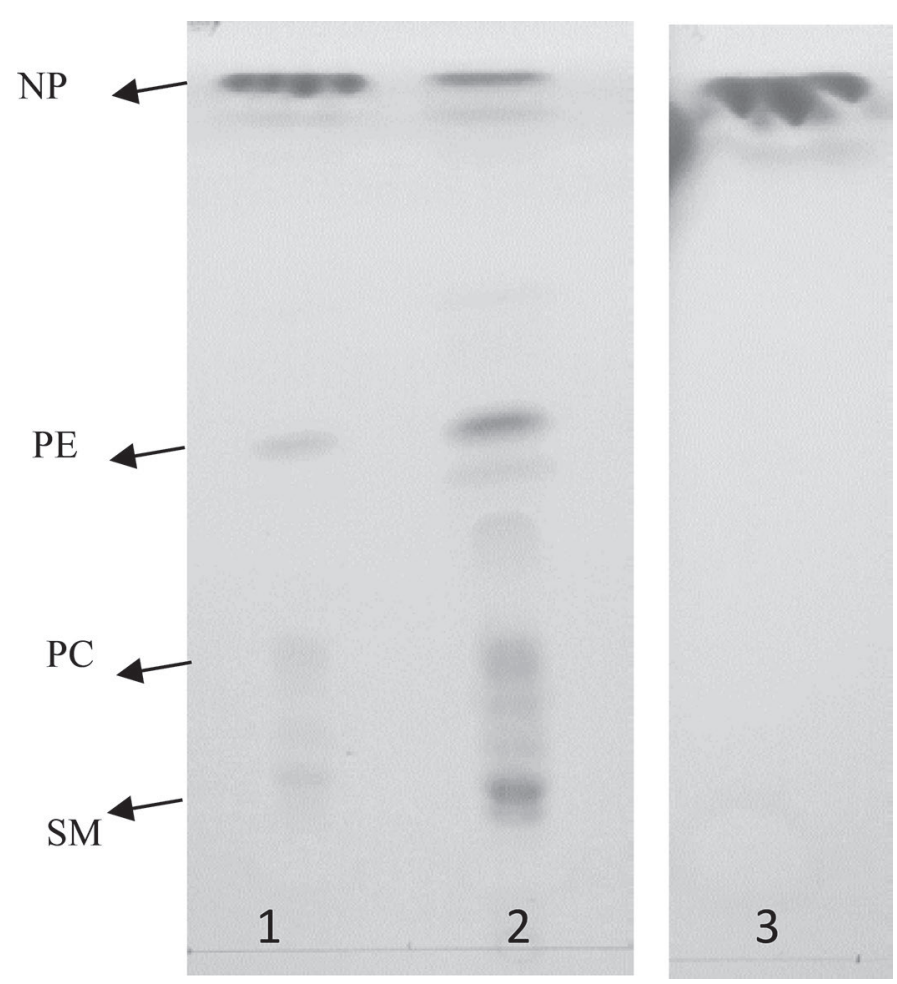

Figure 3. Thin layer chromatography of lipid profiles. Lane $1=$ untreated whey protein phospholipid concentrate (as control); lane 2 $=$ spent solids obtained after the first phase of supercritical fluid extraction (SFE) using neat supercritical carbon dioxide $\left(\mathrm{S}-\mathrm{CO}_{2}\right)$; lane 3 $=$ extracted fraction taken from the spent solids after the first phase of $\mathrm{SFE}$ using neat $\mathrm{S}-\mathrm{CO}_{2}$. $\mathrm{NP}=$ nonpolar lipids; $\mathrm{PE}=$ phosphotidylethanolamine; $\mathrm{PC}=$ phosphatidylcholine; $\mathrm{SM}=$ sphingomyelin .
Step 2: PL Extraction. Phospholipids apparently have limited solubility in neat $\mathrm{S}_{-} \mathrm{CO}_{2}$, so ethanol was added as a co-solvent in the second phase of SFE process to increase the polarity of extraction and solvent strength of $\mathrm{S}_{-} \mathrm{CO}_{2}$. To further elucidate the effect of different SFE parameters on PL recovery, in the second step of the extraction process, the spent solids from the first SFE extraction were subjected to different ethanol concentrations $(10,15$, and $20 \%$ ), extraction pressures (35.0, 41.4, and 55.0 MPa), and temperatures (40 and $60^{\circ} \mathrm{C}$ ). Figure 4 shows the results of total PL recovery (as g/100 g of fat) for each treatment.

Ethanol Concentration. Statistical analysis showed ethanol concentration had a significant effect on total PL recovery from spent solids $(P<0.05)$. As Figure 4 shows, increasing the ethanol level from 10 to $15 \%$ in $\mathrm{S}_{-} \mathrm{CO}_{2}$ significantly increased the amount of recovered PL at both extraction temperatures (40 and $\left.60^{\circ} \mathrm{C} ; P<0.05\right)$. Although there was no significant difference in PL content between 15 and $20 \%$ ethanol, more PL was found at the $20 \%$ ethanol concentration $(P>0.05)$, indicating that ethanol is an excellent cosolvent for PL extraction in the SFE-S- $\mathrm{CO}_{2}$ process, and increased ethanol concentration at $20 \%$ extracted more PL from WPPC. In Montanari et al. (1996), ethanol had a similar effect on PL extraction; increasing ethanol concentration from 5 to $20 \mathrm{~mol} \%$ in $\mathrm{S}_{-} \mathrm{CO}_{2}$ significantly increased the amount of total PL extracted from soybean flakes. More recently, Barry et al. (2017) reported that running the SFE-S- $\mathrm{CO}_{2}$ process $(30.0$ $\mathrm{MPa}, 40^{\circ} \mathrm{C}$ ) with $20 \%$ ethanol concentration helped in extracting high purity of PL $(56.24 \pm 0.075 \%$ on dry basis) from buttermilk hydrolysate, whereas a lower amount of ethanol at $10 \%$ could not extract the PL fraction. Overall, the optimal ethanol concentration for producing the highest amount of PL from spent solids was $20 \%$ ethanol. When this percentage was used, the average amount of PL extracted was found to be 26.26 g per $100 \mathrm{~g}$ of fat at $35.0 \mathrm{MPa} / 60^{\circ} \mathrm{C}$ (Figure $4-\mathrm{A}$ ), 25.85 $\mathrm{g}$ per $100 \mathrm{~g}$ of fat at $41.5 \mathrm{MPa} / 60^{\circ} \mathrm{C}$ (Figure $4-\mathrm{B}$ ), and $26.72 \mathrm{~g}$ per $100 \mathrm{~g}$ of fat at $55.0 \mathrm{MPa} / 40^{\circ} \mathrm{C}$ (Figure 4-C).

Extraction Temperature and Pressure. We also observed that extraction temperature and pressure had a minor effect on the extraction of PL from spent solids, but no significant difference was observed $(P$ $>0.05)$. Although their effects were not as significant as ethanol concentration, extraction temperature and pressure are still the important factors in PL recovery in SFE-S- $\mathrm{CO}_{2}$ process. The total PL content was found to slightly increase when the extraction temperature was increased from 40 to $60^{\circ} \mathrm{C}$. In addition, extraction pressure at 55.0 MPa instead of 35.0 or $41.4 \mathrm{MPa}$ also tended to show more PL recovered from spent solids during SFE-S- $\mathrm{CO}_{2}$ process (Figure 4). 


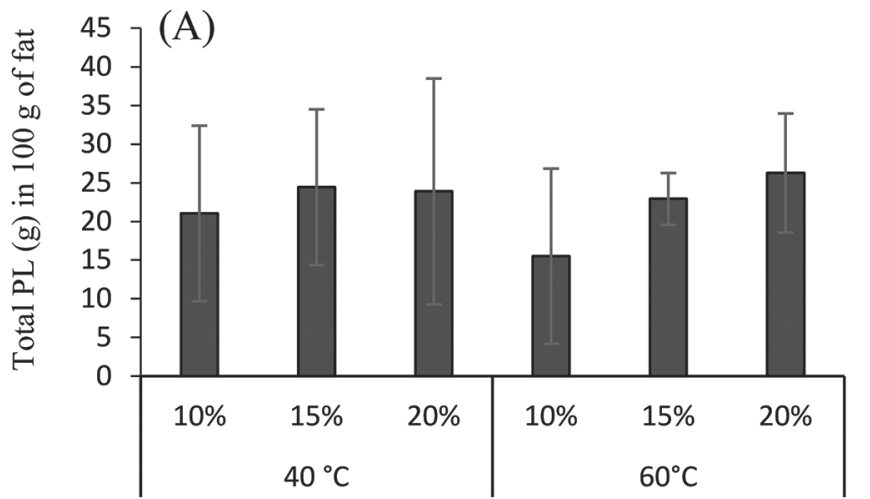

Treatment (ethanol concentration and temperature)

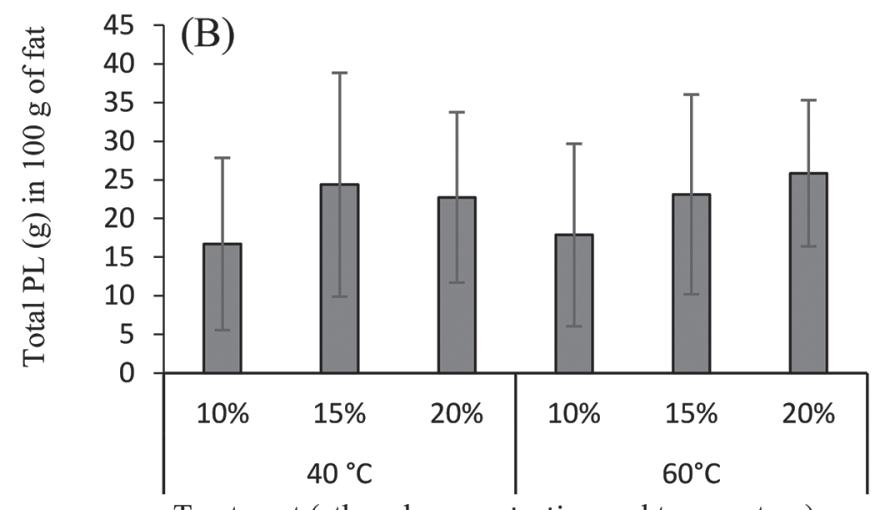

Treatment (ethanol concentration and temperature)

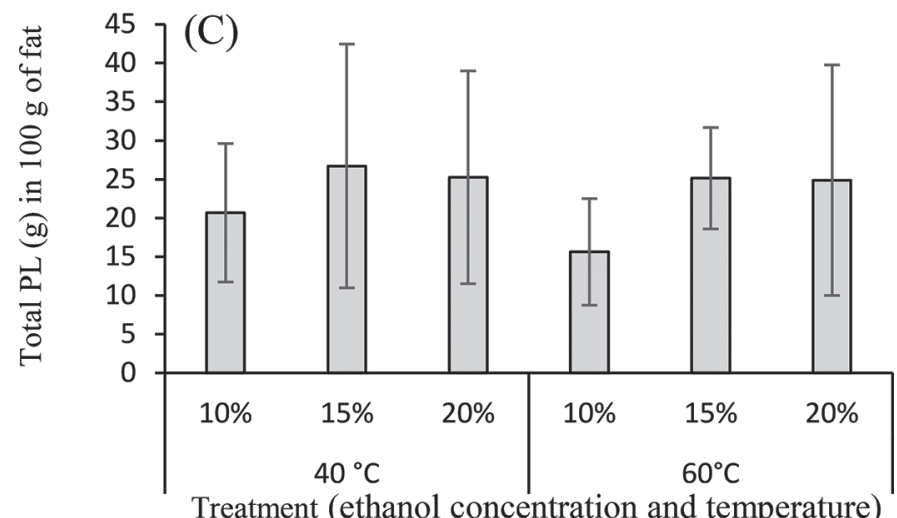

Figure 4. Effect of temperature $\left(40\right.$ and $\left.60^{\circ} \mathrm{C}\right)$ and concentration of ethanol $(10,15$, and $20 \%)$ on the amount of total polar lipids presented in $100 \mathrm{~g}$ of fat from various operating supercritical fluid extraction pressures: (A) 35.0, (B) 41.4, and (C) 55.0 MPa. The means of triplicate extractions $(\mathrm{n}=3)$ are shown; error bars represent SD. PL $=$ phospholipid.

To confirm with the results of the HPLC analysis, TLC was also used as a qualitative check for lipid profiles in the extracted fraction. Figure $5 \mathrm{~A}$ and $\mathrm{B}$ show the TLC results for all the SFE extraction trials. Lipid extracts obtained after the second phase of SFE comprised most of the polar lipids, with a higher concentration of SM followed by PC and PE for the extraction conditions. As with the HPLC results, the intensity of PL bands for SM, PC, and PE was consistently lower at $10 \%$ ethanol than 15 and $20 \%$ ethanol, meaning that a high concentration of PL could not be recovered at low levels of ethanol. However, no significant differences were observed for all of the extraction temperatures and pressures, so the SFE process using a mixture of $\mathrm{S}-\mathrm{CO}_{2}$ and ethanol could effectively extract PL from the spent solids and generate a PL-enriched lipid extract.

Overall, the results confirmed that the SFE process with neat $\mathrm{S}-\mathrm{CO}_{2}$ modified with ethanol could effectively produce a PL-enriched lipid fraction from WPPC. Considering the cost of a high-temperature and high-pressure process, not to mention additional safety concerns, the best conditions under which to operate SFE for PL extraction are $40^{\circ} \mathrm{C}$ and $35.0 \mathrm{MPa}$ with $15 \%$ ethanol concentration. These conditions will be the most cost effective for achieving of the best PL extraction with the average $26.26 \mathrm{~g} / 100 \mathrm{~g}$ of fat, which was almost 3 times higher than 10.42 to $13.24 \mathrm{~g}$ of $\mathrm{PL} / 100 \mathrm{~g}$ of fat using conventional solvent extraction. Furthermore, the total PL content (5.37\%, DM basis) recovered from WPPC in our study was similar or even higher than the values reported in previous studies, like $4.86 \%$ in whey cream, $5.14 \%$ in whey butter, $2.01 \%$ in whey buttermilk, and 3.0 to $3.2 \%$ in whey cream buttermilk on a DM basis (Spence et al., 2009a; Costa et al., 2010).

\section{PL Composition of SFE-Treated WPPC}

To further understand the effect of ethanol concentration and its effect, combined with extraction temperature, on PL composition at $35.0 \mathrm{MPa}$ using $\mathrm{S}_{-} \mathrm{CO}_{2}$ $\mathrm{SFE}$, the distribution of each individual PL was quantified by HPLC; the amount of each PL was expressed as $\mathrm{g} / 100 \mathrm{~g}$ of fat in Figure 6 . The major PL extracted from WPPC were SM, PC, and PE, confirming the study by Walstra et al. (2006). Generally, PL fractions extracted from the MFGM are reported as SM, PC, PE, PS, and PI, with SM and PS of particular interest because they are associated with many health benefits (Barenholz and Thompson, 1999). Figure 6 shows that the distributions for SM, PE, and PS are similar among the SFE-treated WPPC samples throughout the extraction process; however, the amounts of these lipids vary with different extraction temperatures and ethanol concentrations. It was observed that the SM level in lipid fractions significantly increased $(P<0.05)$ when ethanol concentrations were elevated from 10 to $15 \%$ and from 15 to $20 \%$ at both extraction temperatures, suggesting that the extraction of SM was sensitive to ethanol changes in the SFE process. With a higher ethanol concentration, the polarity of $\mathrm{S}^{-\mathrm{CO}_{2}}$ system 
was greatly improved, which favors the extraction of SM because this is the most polar PL class in WPPC (Christie and Han, 2010). On the other hand, a lower extraction temperature at $40^{\circ} \mathrm{C}$ with $20 \%$ ethanol resulted in a lipid fraction from WPPC with the highest SM content (11.07 g/100 g of fat), significantly higher than that at $60^{\circ} \mathrm{C}$ treatment $(P<0.05)$. Compared with SM content in LLE treated WPPC, however, the SFE process was 3 to 4 times more efficient in extracting SM when performed at $40^{\circ} \mathrm{C}$ extraction with $20 \%$ ethanol. Similarly, PE, one of the more important members of the PL class, was also found to be sensitive to the ethanol change in the SFE process. We found $\mathrm{PE}$ concentration increased significantly as ethanol concentration was increased from 10 to $15 \%$ for all extraction temperatures; however, PE content decreased significantly when ethanol was increased to $20 \%(P<$ 0.05 ). According to Figure 6, the highest yield of PE $(7.2 \mathrm{~g} / 100 \mathrm{~g}$ of fat) was achieved using $15 \%$ ethanol at $40^{\circ} \mathrm{C}$. At the higher ethanol concentration, PE extrac- tion from lipid fraction was not as efficient as for SM during SFE extraction, which suggests that PE has less affinity to ethanol than $\mathrm{SM}$ in $\mathrm{S}-\mathrm{CO}_{2}$ solvent. For all extraction temperatures, $\mathrm{PC}$ content did not change significantly when ethanol concentration increased from 10 to $20 \%$. Although PC concentration increased slightly when ethanol concentration was increased from 10 to $15 \%$, the difference was not significant $(P>0.05)$. The highest amount of PC $(10.07 \mathrm{~g} / 100 \mathrm{~g}$ of fat $)$ extracted from the lipid fraction was at $15 \%$ ethanol and $40^{\circ} \mathrm{C}$ (Figure 6), which was 3 times higher than that in the LLE-treated WPPC. Unlike SM and PE, PC recovery during SFE was not significantly affected by changes in ethanol or extraction temperature.

Thus, individual PL extracted from WPPC using SFE followed the order: SM (11.07 g/100 $\mathrm{g}$ of fat) $>\mathrm{PC}(10.07 \mathrm{~g} / 100 \mathrm{~g}$ of fat $)>\mathrm{PE}(7.2 \mathrm{~g} / 100 \mathrm{~g}$ of fat). When compared with the initial content of PL obtained by LLE (Table 2), the lower amounts of SM, $\mathrm{PC}$, and $\mathrm{PE}$ in WPPC indicate that the SFE process
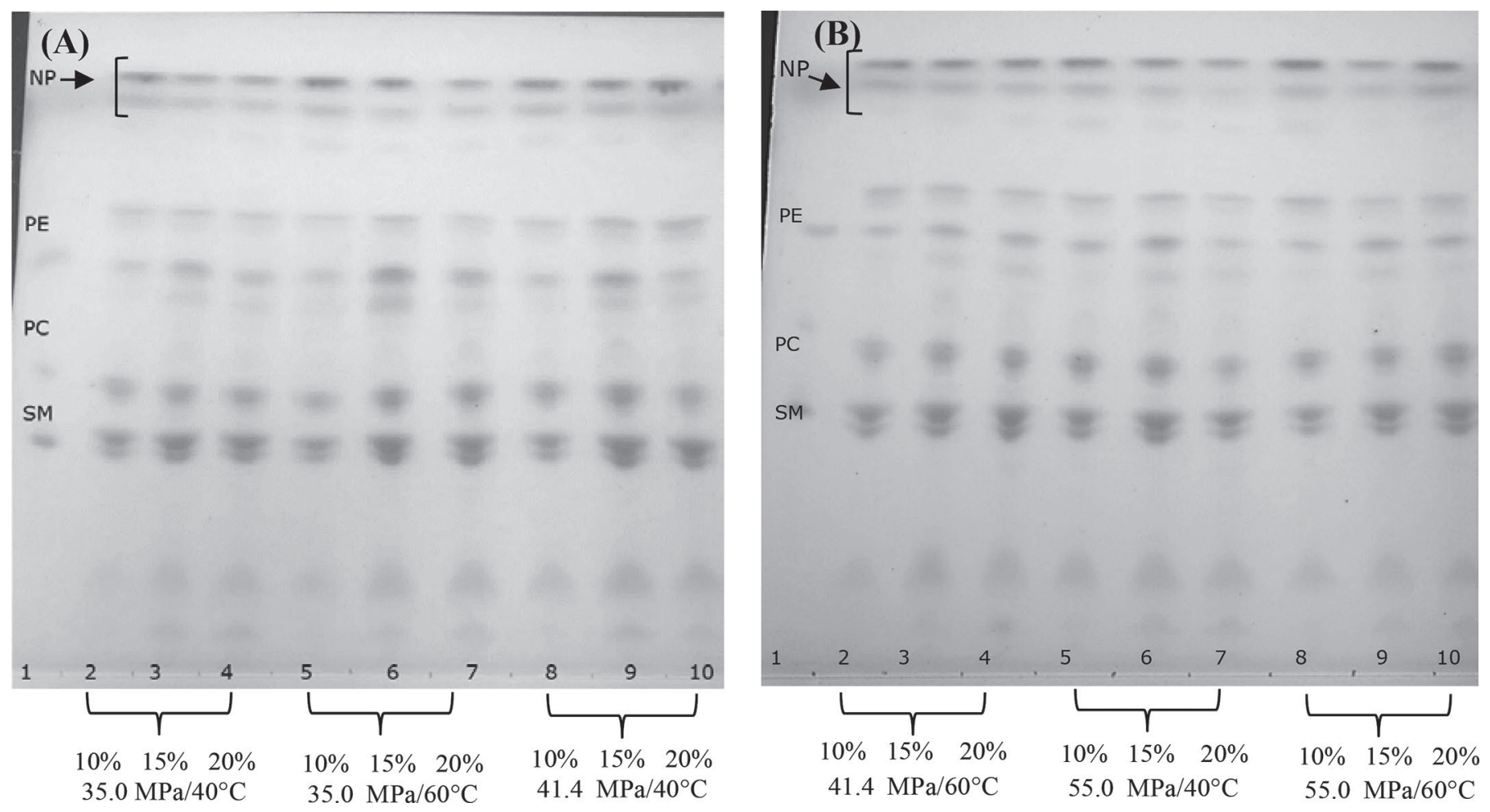

Figure 5. Thin layer chromatograph showing lipid profiles of extracted fractions taken from the exhausted solids after the second phase of supercritical fluid extraction (SFE) using neat supercritical carbon dioxide with ethanol (10, 15, and 20\%) at extraction pressures of 35.0, 41.4, and $55.0 \mathrm{MPa}$, and temperatures of 40 and $60^{\circ} \mathrm{C}$. Sample order in panel A: lane 1 = standards; lanes 2 to 4 are lipids extracted after step 2: 35.0 $\mathrm{MPa}, 40^{\circ} \mathrm{C}$, concentration of ethanol at 10,15 , and $20 \%$, respectively. Lanes 5 to 7 are lipids extracted after step $2: 35.0 \mathrm{MPa}, 60^{\circ} \mathrm{C}$, concentration of ethanol at 10,15, and 20\%, respectively. Lanes 8 to 10 are lipids extracted after step 2: $41.4 \mathrm{MPa}, 40^{\circ} \mathrm{C}$, concentration of ethanol at 10 , 15 , and $20 \%$, respectively. Sample order in panel B: lane $1=$ standards; lanes 2 to 4 are lipids extracted after step 2: $41.4 \mathrm{MPa}, 60^{\circ} \mathrm{C}$, concentration of ethanol at 10,15, and $20 \%$, respectively. Lanes 5 to 7 are lipids extracted after step 2: $55.0 \mathrm{MPa}, 40^{\circ} \mathrm{C}$, concentration of ethanol at 10,15 , and $20 \%$, respectively. Lanes 8 to 10 are lipids extracted after step 2: $55.0 \mathrm{MPa}, 60^{\circ} \mathrm{C}$, concentration of ethanol at 10,15 , and $20 \%$, respectively. $\mathrm{NP}=$ nonpolar lipids; $\mathrm{PE}=$ phosphatidylethanolamine; $\mathrm{PC}=$ phosphatidylcholine; $\mathrm{SM}=$ sphingomyelin. 
Table 3. Average emulsifying capacity (EC) and water-holding capacity (WHC) of whey protein phospholipid concentrate (WPPC) powder and exhausted solids ${ }^{1}$

\begin{tabular}{lcc}
\hline & \multicolumn{2}{c}{ EC } \\
\cline { 2 - 3 } Sample & $\begin{array}{c}(\mathrm{mL} \text { of oil } / \\
\text { g of } 5 \% \text { solution })\end{array}$ & WHC $(\%)$ \\
\hline WPPC & $5.43 \pm 0.29^{\mathrm{a}}$ & $40.68 \pm 1.07^{\mathrm{a}}$ \\
Exhausted solids & $6.25 \pm 0.17^{\mathrm{b}}$ & $57.03 \pm 3.30^{\mathrm{b}}$ \\
\hline
\end{tabular}

${ }^{\mathrm{a}, \mathrm{b}}$ Means within a column with different superscripts differ $(P<0.05)$. ${ }^{1} \mathrm{n}=2$; mean \pm relative deviations from the mean.

and ethanol as a co-solvent extracted more PL than the LLE method. This differs from Levin et al. (2016), who reported an extraction of 0.28 to $0.43 \%$ of $\mathrm{PE}$ and 0.27 to $0.39 \%$ of $\mathrm{PC}$ on a total fat basis, but extracted no SM. A recent study by Price et al. (2018) used a sequential ethanol extraction while investigating the PL composition of WPPC and found that PC and PE were the most abundant PL in the MFGM followed by SM, whereas other PL such as PS and PI were less than $10 \%$ of total PL. Based on these studies, the proportion of individual PL extracted from WPPC can be varied depending on different extraction and analysis methods; other PL such as PS and PI were not observed in SFE-treated WPPC in this study, which was probably because the detection using UV wavelength was not sensitive enough for analysis of trace quantities of $\mathrm{PL}$ in WPPC. Therefore, the SFE-S- $\mathrm{CO}_{2}$ process may require increasing the ethanol concentration further to improve the extraction efficiency (Barry et al., 2017). Overall, our study clearly demonstrated that the SFE process with $\mathrm{S}_{-} \mathrm{CO}_{2}$ and ethanol as a co-solvent was promising for concentrating bioactive lipids such as SM, PE, and PC in the MFGM in WPPC, and modifying ethanol concentration affected significantly the proportion of $\mathrm{SM}$ and PE extracted during the SFE process. In addition, a lower extraction temperature of $40^{\circ} \mathrm{C}$ tended to result in more of each PL fraction.

\section{Functional Properties of the Exhausted Solids}

After SFE treatment, because most nonpolar and polar lipids were removed from WPPC and the remaining fraction primarily comprises proteins (mostly denatured), as could be expected, the total protein content in the exhausted solids increased to approximately $72 \%$ (dry basis; data not shown). Therefore, we evaluated the functional characteristics, including the emulsifying capacity and WHC, of WPPC untreated samples as well as the exhausted solids obtained after SFE-S-CO $\mathrm{CO}_{2}$ extraction $\left(55.0 \mathrm{MPa}, 40^{\circ} \mathrm{C}\right.$, and $15 \%$ ethanol). Table 3 shows all the results.

Compared with the original WPPC (control), the emulsifying capacity of the exhausted solids extracted from WPPC improved significantly from $5.43 \pm 0.29$ to $6.25 \pm 0.17 \mathrm{~mL}$ of oil $/ \mathrm{g}$ of solution $(P<0.05)$. The emulsifying capacity was primarily affected by the level

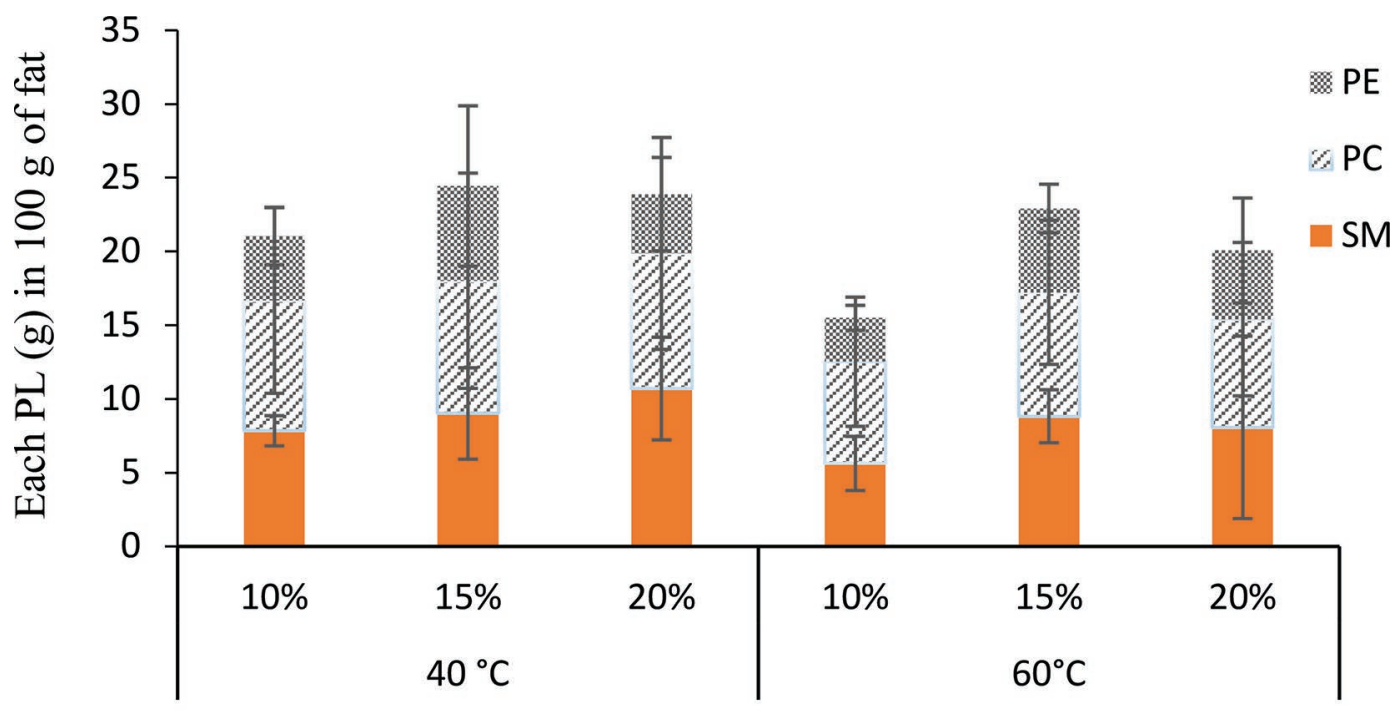

Treatment (ethanol concentration and temperature)

Figure 6. Effect of concentration of ethanol (10, 15, and 20\%) on the amount of sphingomyelin (SM), phosphatidylcholine (PC), and phosphotidylethanolamine $(\mathrm{PE})$ present in exhausted solids from the supercritical fluid extraction process at 35.0 MPa with supercritical carbon dioxide at extraction temperature of 40 and $60^{\circ} \mathrm{C}$ and ethanol concentrations of 10,15 , and $20 \%$. The average of triplicate samples are shown; bars indicate SD. PL = phospholipid. 
of denatured proteins present between the water and oil interfaces, so the increase (approximately 15\%) in the emulsifying capacity of exhausted solids probably correlates to the higher amounts of denatured whey proteins, aiding in the emulsion process. Moreover, the lower amount of residual lipids in the exhausted solids may strengthen the protein-protein interactions at the interfaces (Blecker et al., 1997).

The WHC of WPPC in our study was measured at $\mathrm{pH} 7.0$, with a resulting $40.68 \pm 1.07 \%$, relatively lower than whey protein concentration at 3.3 to $10.0 \%$ water release (Veith and Reynolds, 2004), indicating that native WPPC has fewer denatured proteins available in the solution to hold water. Compared with WPPC, the exhausted solids obtained after SFE extraction had superior WHC with an average of $57.03 \pm 3.30 \%(P$ $<0.05)$. This may correlate to a higher concentration of denatured proteins released from the lipid fraction after the SFE process, thus increasing the WHC. This may also be due to the high heat treatment used in the SFE process inducing more proteins to denature and enhancing WHC.

\section{CONCLUSIONS}

In this study, our results showed that this unique 2-step SFE process with neat $\mathrm{S}-\mathrm{CO}_{2}$ and ethanol as a co-solvent is an efficient extraction method for concentrating a PL-rich fraction from WPPC. The TLC results showed that the nonpolar lipids were removed from WPPC by neat $\mathrm{S}_{-} \mathrm{CO}_{2}$ in the first SFE step. Moreover, polar solvent ethanol is needed to improve the polarity of $\mathrm{S}_{-} \mathrm{CO}_{2}$ solvent and was successful in extracting 3 major classes of PL (SM, PC, and PE) from the spent solids in the second SFE step. Our results also revealed that the extraction efficiency of PL was significantly affected by altering the ethanol concentration in $\mathrm{S}-\mathrm{CO}_{2}$, whereas extraction temperature and pressure had little effect. The optimal extraction condition was $35.0 \mathrm{MPa}, 40^{\circ} \mathrm{C}$, and $15 \%$ ethanol, generating $26.26 \mathrm{~g}$ of total PL/100 g of fat. In summary, this work proves that SFE is a safe and economical method for extracting high-value PL from WPPC while operating at a relatively a low temperature and pressure.

\section{ACKNOWLEDGMENTS}

We thank Midwest Dairy Foods Research Center (St. Paul, MN) for their financial support. This project is Kansas State Research and Extension contribution number 18-150-J. This work was partially supported by the USDA National Institute of Food and Agriculture, Hatch project 1014344.

\section{REFERENCES}

American Dairy Products Institute. 2016. Whey protein phospholipid concentrate standard. American Dairy Products Institute, Elmhurst, IL.

AOAC International. 2016. Official Methods of Analysis. 20th ed. Association of Analytical Communities, Rockville, MD.

Astaire, J. C., R. Ward, J. B. German, and R. Jiménez-Flores. 2003. Concentration of polar MFGM lipids from buttermilk by microfiltration and supercritical fluid extraction. J. Dairy Sci. 86:22972307.

Barenholz, Y., and T. E. Thompson. 1999. Sphingomyelin: Biophysical aspects. Chem. Phys. Lipids 102:29-34.

Barry, K. M., T. G. Dinan, and P. M. Kelly. 2017. Pilot scale production of a phospholipid-enriched dairy ingredient by means of an optimised integrated process employing enzymatic hydrolysis, ultrafiltration and super-critical fluid extraction. Innov. Food Sci. Emerg. Technol. 41:301-306.

Blecker, C., M. Paquot, I. Lamberti, A. Sensidoni, G. Lognay, and C. Deroanne. 1997. Improved emulsifying and foaming of whey proteins after enzymic fat hydrolysis. J. Food Sci. 62:48-52.

Bund, R. K., and R. W. Hartel. 2013. Blends of delactosed permeate and pro-cream in ice cream: Effects on physical, textural and sensory attributes. Int. Dairy J. 31:132-138.

Chojnacka, A., W. Gładkowski, G. Kiełbowicz, and C. Wawrzeńczyk. 2009. Enzymatic enrichment of egg-yolk phosphatidylcholine with alpha-linolenic acid. Biotechnol. Lett. 31:705-709.

Christie, W. X., and X. Han. 2010. Lipid Analysis: Isolation, Separation, Identification and Lipidomic Analysis. 4th ed. The Oily Press, Bridgwater, UK.

Contarini, G., and M. Povolo. 2013. Phospholipids in milk fat: Composition, biological and technological significance, and analytical strategies. Int. J. Mol. Sci. 14:2808-2831.

Corredig, M., R. R. Roesch, and D. G. Dalgleish. 2003. Production of a novel ingredient from buttermilk. J. Dairy Sci. 86:2744-2750.

Costa, M. R., X. E. Elias-Argote, R. Jiménez-Flores, and M. L. Gigante. 2010. Use of ultrafiltration and supercritical fluid extraction to obtain a whey buttermilk powder enriched in milk fat globule membrane phospholipids. Int. Dairy J. 20:598-602.

Elst, K., L. V. Ginneken, and H. Weyten. 2003. Selective extraction of phospholipids from egg yolk with supercritical $\mathrm{CO}_{2}$. Pages $373-378$ in Proc. Sixth International Symposium on Supercritical Fluids, ISASF. Versailles, France.

Gülseren, İ., A. Guri, and M. Corredig. 2012. Encapsulation of tea polyphenols in nanoliposomes prepared with milk phospholipids and their effect on the viability of HT-29 human carcinoma cells. Food Dig. 3:36-45.

Hartmann, P., A. Szabó, G. Eros, D. Gurabi, G. Horváth, I. Németh, M. Ghyczy, and M. Boros. 2009. Anti-inflammatory effects of phosphatidylcholine in neutrophil leukocyte-dependent acute arthritis in rats. Eur. J. Pharmacol. 622:58-64.

Hauff, S., and W. Vetter. 2009. Quantification of fatty acids as methyl esters and phospholipids in cheese samples after separation of triacylglycerides and phospholipids. Anal. Chim. Acta 636:229-235.

Hawke, J. C. 1959. The fatty acids of phosphatidylethanolamine and phosphatidylcholine from hen's egg. Biochem. J. 71:588-592.

Herrero, M., A. Cifuentes, and E. Ibañez. 2006. Sub- and supercritical fluid extraction of functional ingredients from different natural sources: Plants, food-by-products, algae and microalgae: A review. Food Chem. 98:136-148.

Ishihara, K., H. Oshida, Y. Endo, T. Ueda, A. Watanabe, and N Nakabayashi. 1992. Hemocompatibility of human whole blood on polymers with a phospholipid polar group and its mechanism. J. Biomed. Mater. Res. 26:1543-1552.

Kamili, A., E. Wat, R. W. Chung, S. Tandy, J. M. Weir, P. J. Meikle, and J. S. Cohn. 2010. Hepatic accumulation of intestinal cholesterol is decreased and fecal cholesterol excretion is increased in mice fed a high-fat diet supplemented with milk phospholipids. Nutr. Metab. (Lond.) 7:90.

Khaw, K.-Y., M.-O. Parat, P. N. Shaw, and J. R. Falconer. 2017. Solvent supercritical fluid technologies to extract bioactive com- 
pounds from natural sources: A review. Molecules https://doi.org/ 10.3390/molecules22071186.

Kuchta, A. M., P. M. Kelly, C. Stanton, and R. A. Devery. 2012. Milk fat globule membrane - A source of polar lipids for colon health? A review. Int. J. Dairy Technol. 65:315-333.

Levin, M. A., K. J. Burrington, and R. W. Hartel. 2016. Composition and functionality of whey protein phospholipid concentrate and delactosed permeate. J. Dairy Sci. 99:6937-6947.

Montanari, L., P. Fantozzi, J. M. Snyder, and J. W. King. 1999. Selective extraction of phospholipids from soybeans with supercritical carbon dioxide and ethanol. J. Supercrit. Fluids 14:87-93.

Montanari, L., J. W. King, G. R. List, and K. A. Rennick. 1996. Selective extraction of phospholipid mixtures by supercritical carbon dioxide and cosolvents. J. Food Sci. 61:1230-1234.

Morin, P., R. Jiménez-Flores, and Y. Pouliot. 2004. Effect of temperature and pore size on the fractionation of fresh and reconstituted buttermilk by microfiltration. J. Dairy Sci. 87:267-273.

Nisha, A., K. Udaya Sankar, and G. Venkateswaran. 2012. Supercritical $\mathrm{CO}_{2}$ extraction of Mortierella alpina single cell oil: Comparison with organic solvent extraction. Food Chem. 133:220-226.

Noh, S. K., and S. I. Koo. 2004. Milk sphingomyelin is more effective than egg sphingomyelin in inhibiting intestinal absorption of cholesterol and fat in rats. J. Nutr. 134:2611-2616.

Price, N., T. Fei, S. Clark, and T. Wang. 2018. Extraction of phospholipids from a dairy by-product (whey protein phospholipid concentrate) using ethanol. J. Dairy Sci. 101:8778-8787.

Rombaut, R., K. Dewettinck, and J. Van Camp. 2007. Phospho- and sphingolipid content of selected dairy products as determined by HPLC coupled to an evaporative light scattering detector (HPLCELSD). J. Food Compos. Anal. 20:308-312.

Sánchez-Juanesa, F., J. M. Alonsob, L. Zancadaa, and P. Hueso. 2009. Distribution and fatty acid content of phospholipids from bovine milk and bovine milk fat globule membranes. Int. Dairy J. 19:273278.

Schubert, M., C. Contreras, N. Franz, and J. Hellhammer. 2011. Milkbased phospholipids increase morning cortisol availability and improve memory in chronically stressed men. Nutr. Res. 31:413-420.

Singh, H. 2006. The milk fat globule membrane-A biophysical system for food applications. Curr. Opin. Colloid Interface Sci. 11:154163.

Spence, A. J., R. Jimenez-Flores, M. Qian, and L. Goddik. 2009a. Phospholipid enrichment in sweet and whey cream buttermilk powders using supercritical fluid extraction. J. Dairy Sci. 92:23732381

Spence, A. J., R. Jimenez-Flores, M. Qian, and L. Goddik. 2009b. The influence of temperature and pressure factors in supercritical fluid extraction for optimizing nonpolar lipid extraction from buttermilk powder. J. Dairy Sci. 92:458-468.

Veereman-Wauters, G., S. Staelens, R. Rombaut, K. Dewettinck, D. Deboutte, R.-J. Brummer, M. Boone, and P. Le Ruyet. 2012. Milk fat globule membrane (INPULSE) enriched formula milk decreases febrile episodes and may improve behavioral regulation in young children. Nutrition 28:749-752.

Veith, P. D., and E. C. Reynolds. 2004. Production of a high gel strength whey protein concentrate from cheese whey. J. Dairy Sci. 87:831-840.

Walstra, P., J. T. M. Wouters, and T. J. Geurts. 2006. Dairy Science and Technology. CRC/Taylor \& Francis, New York, NY.

Wang, F., Y. Zhao, and P. Wang. 2003. Separation and determination of phospholipids in biological samples by high-performance liquid chromatography. J. Chromatogr. Sci. 41:142-144.

Zhong, Q., and M. Jin. 2008. Enhanced functionalities of whey proteins treated with supercritical carbon dioxide. J. Dairy Sci. 91:490-499. 